A $\mathbf{R}_{\text {Eview }}$

FOOD SCIENCE

RESEARCH JOURNAL

e ISSN-2230-9403 - Visit us : www.researchjournal.co.in

Volume 6 | Issue 1 | April, 2015 |158-166

DOI : $10.15740 / \mathrm{HAS} / \mathrm{FSRJ} / 6.1 / 158-166$

\title{
Food security: Historical perspectives and contemporary concerns
}

\author{
Shikha Saxena and Rajib Dasgupta
}

This paper is an attempt to analyse the food security issues. It encompasses four sections which are dealing with the, Historical perspectives, National Food Security Bill, WTO Agreement on agriculture and the recent debate which is going around on its success and insufficiency.

Key Words : Food security, Public distribution system, Nutrition

How to cite this article : Saxena, Shikha and Dasgupta, Rajib (2015). Food security: Historical perspectives and contemporary concerns. Food Sci. Res. $J ., 6(1): 158-166$.

Author for correspondence :

SHIKHA SAXENA, Centre of Social Medicine and Community Health, School

of Social Sciences, Jawaharlal Nehru University, NEW DELHI, INDIA

Associate Authors' :

RAJIB DASGUPTA, Centre for Social Medicine and Community Health, School

of Social Sciences, Jawaharlal Nehru University, NEW DELHI, INDIA 